\title{
Assessment of Potential Drug-Drug Interactions in an Oncology Unit of a Tertiary Care Teaching Hospital
}

\begin{abstract}
Context: Drug interactions are more common in cancer patients because they consume several medicines such as hormonal substances, anticancer drugs, and adjuvant drugs to treat comorbidities Objectives: To assess the pattern of potential drug-drug interactions (pDDIs) in an oncology unit of a tertiary care teaching hospital. Materials and Methods: A prospective observational study was carried out for 8 months (August 2016 to March 2017). Data on drugs were collected by reviewing the patients' medical records. The drug interactions fact software version such as Micromedex electronic database system, drugs.com interaction checker, and Medscape multidrug interaction checker tool were used to identify and analyze the pattern of pDDIs. Results: A total of 180 patients were enrolled during the study period. Among them, 152 study patients had $84.44 \%$ of pDDIs. Male predominance $(64.4 \%)$ was noted over female (35.6\%). According to the severity of classification of pDDIs, majority of them were moderate $(63.1 \%)$ followed by major $(26.1 \%)$ and minor $(10.1 \%)$ interactions. The interactions that potentially cause QT interval prolongation and irregular heartbeat were the common outcomes of pDDIs. Conclusions: The incidence of pDDIs among cancer patients was $84.44 \%$. The most common interacting drug pair in the study population was found to be dexamethasone + aprepitant [41 (26.9\%)] followed by cisplatin + dexamethasone [32 $(21.05 \%)]$ and other interacting pairs. To avoid harmful effects, screening of pDDIs should take place before administering the therapy.
\end{abstract}

Keywords: Antineoplastic agents, chemotherapy, drug interactions

\section{Introduction}

Drug interactions are more common in cancer patients because they consume substances, anticancer drugs, and adjuvant drugs to treat comorbidities. ${ }^{[1,2]}$ The risk of drug-drug interactions (DDIs) increases in elderly patients due to their increased age, physiological changes, and comorbidities. ${ }^{[3]}$ Cytotoxic drugs have narrow therapeutic index, so increases or decreases in the cytotoxic activity result in toxic effect. ${ }^{[4]}$

Approximately, $60 \%$ of the patients undergoing treatment for cancer may develop at least one DDI, of which $30 \%$ require medical intervention. QT prolongation, gastrointestinal (GI) toxicity, and central nervous system depression are the most common results of pharmacodynamic DDIs. Most of these potential drug-drug interactions (pDDIs) are left unnoticed or not given proper intervention due to the lack of healthy professional relationship between medical

This is an open access journal, and articles are Attribution-NonCommercial-ShareAlike 4.0 License, which allows others to remix, tweak, and build upon the work non-commercially, as long as appropriate credit is given and the new creations are licensed under the identical terms.

For reprints contact: reprints@medknow.com several medications such as hormonal distributed under the terms of the Creative Commons oncologists, pharmacists, and general practitioners. ${ }^{[5]}$

Before starting chemotherapy, it is necessary to check the pDDIs for the successful usage of drug therapy and to improve the quality of life of the patient. Clinical pharmacists require good knowledge in monitoring DDIs and should advise patients regarding the proper use of drugs. Hence, the present study was aimed to assess the patterns of pDDIs in the oncology unit of a tertiary care teaching hospital.

\section{Materials and Methods}

A prospective observational study was carried out for 8-month period (from August 2016 to March 2017) in the inpatient unit of oncology unit at Justice K.S. Hegde Charitable Hospital, Mangaluru. Before starting the study, the study protocol was approved by the Institutional Ethical Committee (Ref no: NIST. EC/EC/65/2016-2017). Either patients of gender with $>18$ years and diagnosed with

\footnotetext{
How to cite this article: Vayalil RK, Shetty KJ, Mateti UV. Assessment of potential drug-drug interactions in an oncology unit of a tertiary care teaching hospital. Indian J Med Paediatr Oncol 2018;39:436-42.
}

\section{Ramya Kuzhikattu Vayalil, K Jayarama Shetty ${ }^{1}$, Uday Venkat Mateti}

Department of Pharmacy Practice, NGSM Institute of Pharmaceutical K.S. Hegde Medical Academy, Justice K.S. Hegde Charitable Hospital, Nitte University, Paneer, Deralakatte, Mangaluru, Karnataka, India Sciences, ${ }^{\prime}$ Department of Radiology and Oncology,

\author{
Address for correspondence: \\ Dr. Uday Venkat Mateti, \\ Department of Pharmacy \\ Practice, NGSM Institute \\ of Pharmaceutical \\ Sciences, Nitte University, \\ Paneer, Deralakatte, \\ Mangaluru - 575018 , \\ Karnataka, India. \\ E-mail: udayvenkatmateti@ \\ gmail.com
}

Access this article online Website: www.ijmpo.org DOI: 10.4103/ijmpo.ijmpo_93_17 Quick Response Code:

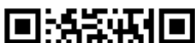


solid tumor or hematological malignancy were included in the study. Patients who referred to oncology department for consultation, patients who are not willing to participate, pregnant and lactating women were excluded from the study.

The data were collected from patients' treatment chart. Patient medication details were collected on the daily basis and recorded in the drug interactions' documentation form. The pDDIs were those not observed in the patients but they give a signal for the detection of interactions. Micromedex electronic database system, drugs.com interaction checker, and Medscape multidrug interaction checker tool were used to identify the pattern of pDDIs. ${ }^{[6,7]}$ Micromedex contains a separate section on DDIs known as the Drug-REAX System, Denver, Colorado State, US. On entering the drugs one by one, the program lists the possible interactions and categorizes interactions according to their interaction effect, severity (major, moderate, and minor), onset (rapid and delayed), and documentation status (excellent, good and fair). Medscape and drugs.com contain a separate tool for detecting interactions known as the multidrug interaction checker tool. On entering the drugs one by one, the program lists the possible interactions and categorizes interactions according to their interaction effect, severity (major, moderate, and minor), and management. The required guidance to manage particular pDDI was provided to the physician by referring information provided in drug interaction tools.

\section{Statistical analysis}

Descriptive statistics were used to describe the demographic characteristic of patients, cancer type, treatment, comorbidities, number of drugs prescribed per patient, and classification of drug interactions. Data analysis was carried out using the Statistical Package for Social Studies (SPSS) version 16 (SPSS Inc., South Asia, Bengaluru).

\section{Results}

A total of 180 patients were included during the study period. Among them, 152 study patients had 84.44\% of pDDIs. Male predominance $(64.4 \%)$ was noted over female $(35.6 \%)$. The mean age of the study population was $53.6 \pm 12.4$ years. Most of the patients were in the age group of 50-59 years $(33.3 \%)$ followed by 60-69 years (23.9\%). Majority of the patients had no family history of cancer $(81.7 \%)$ and there was no history of comorbidities (83.8\%). Hypertension [11 (7.2\%)] was found to be the most common comorbidity observed in cancer patients with pDDIs followed by diabetes mellitus $9(5.9 \%)$.

Out of 180 patients, $18.3 \%$ of patients had a history of smoking followed by alcohol and tobacco usage. Majority of the patients were hospitalized for 1-9 days. The median duration of the hospital stay was found to be 9 days. Out of 180 patients, breast cancer [24 (15.7\%)] with pDDIs was the most common cancer type in the study population. The median number of medications received by the study population was found to be eight per day. Most of the pDDIs were observed in patients who had undergone 6-10 cycles of chemotherapy [70 (67.3\%)], followed by $11-15$ cycles $[26(14.4 \%)]$. Patient characteristics and statistical significance of the results are summarized in Table 1.

Among anticancer agents that cause pDDIs, alkylating agent + corticosteroids [32 (21.05\%)] were found to be the most common interacting group in cancer patients followed by corticosteroids + mitotic inhibitors [31 $(20.3 \%)]$, alkylating + mitotic inhibitors [26 (17.1\%)] and the other interacting groups are summarized in Table 2. Similarly, in supportive care agents, corticosteroids + aprepitant [34 (22.3\%)] were found to be the common interacting pair in cancer patients followed by histamine $\mathrm{H} 2$ antagonist + analgesics, 19 (12.5\%), and the other interacting groups are described in Table 3.

Out of 152 patients, 659 pDDIs were observed in the study. The most common interacting drug pair in the study population was found to be dexamethasone + aprepitant [41 (26.9\%)] followed by cisplatin + dexamethasone [32 $(21.05 \%)]$ the other interacting pairs are summarized in Tables 4 and 5. QT interval prolongation [62 (40.1\%)] was found to be the most common pDDI outcome in cancer patients.

According to the severity of drug interactions, $416(63.1 \%)$ of pDDIs were moderate followed by major [172 (26.1\%)] and minor [67 (10.1\%)]. Among the 659 interactions, 563 $(85.4 \%)$ of pDDIs did not specify their onset [23 $(3.4 \%)]$ were delayed onset, and $73(11 \%)$ were rapid onset. The documentation levels of significance of pDDIs were fair [556 (84.3\%)] followed by good [66 (10\%)] and rapid [37 $(5.6 \%)]$.

\section{Discussion}

Drug-drug interactions (DDIs) occur when one drug increases or decreases the efficacy of another drug, when both are administered together. When the interaction causes an increase in the effect of one or both of the drugs, that interaction is called synergistic effect. The opposite effect to synergetic effect is termed antagonism. ${ }^{[8]}$

The current study analyzed the pattern of pDDIs and their assessment among cancer patients. In this study, it was noticed that male $(64.4 \%)$ patients constituted a major proportion of the study population than females $(35.6 \%)$. Similar result was shown in the study conducted by Leeuwen et al. ${ }^{[9]}$ where it was reported that males $(55 \%)$ were higher than females $(45 \%)$. However, contradictory results were shown in the study conducted by Ussai et al., ${ }^{[10]}$ in which female $(69 \%)$ patients constituted the major proportion of the study population than male patients $(31 \%)$. 


\begin{tabular}{|c|c|c|c|}
\hline Demographic details & $\begin{array}{c}\text { Number of patients with } \\
\text { pDDIs }(n=152)(\%)\end{array}$ & $\begin{array}{c}\text { Number of patients without } \\
\text { pDDIs }(n=28)(\%)\end{array}$ & $\begin{array}{c}\text { Total number of } \\
\text { patients }(n=180)(\%)\end{array}$ \\
\hline \multicolumn{4}{|l|}{ Gender } \\
\hline Male & $101(66.4)$ & $15(53.5)$ & $116(64.4)$ \\
\hline Female & $51(33.6)$ & $13(46.4)$ & $64(35.6)$ \\
\hline \multicolumn{4}{|l|}{ Age groups } \\
\hline $18-29$ & $6(3.9)$ & $2(7.1)$ & $8(4.4)$ \\
\hline $30-39$ & $17(11.1)$ & $1(3.6)$ & $18(10)$ \\
\hline $40-49$ & $29(19)$ & $6(21.4)$ & 35 (19.4) \\
\hline $50-59$ & $51(33.5)$ & $9(32.1)$ & $60(33.3)$ \\
\hline $60-69$ & $38(25)$ & $5(17.8)$ & $43(23.9)$ \\
\hline $70-79$ & $10(6.5)$ & $3(10.7)$ & $13(7.2)$ \\
\hline$>80$ & $1(0.6)$ & $2(7.1)$ & $3(1.7)$ \\
\hline \multicolumn{4}{|l|}{ Comorbidities } \\
\hline HTN & $11(7.2)$ & $2(7.1)$ & $13(7.2)$ \\
\hline Diabetes mellitus & $9(5.9)$ & $1(3.5)$ & $10(5.6)$ \\
\hline Asthma & $2(1.3)$ & $1(3.5)$ & $3(1.7)$ \\
\hline Epilepsy & $3(1.9)$ & $2(7.1)$ & $3(1.7)$ \\
\hline \multicolumn{4}{|l|}{ Social habits } \\
\hline Smoking & $30(19.7)$ & $3(10.7)$ & $33(18.3)$ \\
\hline Alcohol & $22(14.4)$ & $2(7.14)$ & $24(13.3)$ \\
\hline Tobacco & $18(11.8)$ & $1(3.5)$ & $19(10.5)$ \\
\hline \multicolumn{4}{|l|}{ Length of hospital stay } \\
\hline $1-9$ & $77(42.8)$ & $14(7.8)$ & $91(50.6)$ \\
\hline $10-19$ & $29(16.1)$ & $3(1.6)$ & $31(17.2)$ \\
\hline $20-29$ & $12(6.7)$ & $4(2.2)$ & $17(9.4)$ \\
\hline $30-39$ & $23(12.8)$ & $6(3.3)$ & $29(16.1)$ \\
\hline $40-49$ & $5(2.8)$ & - & $5(2.8)$ \\
\hline $50-59$ & $3(1.6)$ & - & $3(1.6)$ \\
\hline $60-69$ & $3(1.6)$ & $1(0.6)$ & $4(2.2)$ \\
\hline \multicolumn{4}{|l|}{ Solid malignancy } \\
\hline Breast & $24(15.7)$ & $2(7.1)$ & $26(14.4)$ \\
\hline Lung & $18(11.8)$ & $5(17.8)$ & $23(12.7)$ \\
\hline Buccal mucosa & $15(9.8)$ & $4(14.2)$ & $19(10.5)$ \\
\hline Esophagus & $10(6.5)$ & $2(7.1)$ & $12(6.6)$ \\
\hline Stomach & $13(8.5)$ & $3(10.7)$ & $16(8.8)$ \\
\hline Gynecologic & $4(2.6)$ & $5(17.8)$ & $9(5)$ \\
\hline Gentio-urinary & $3(1.9)$ & $1(3.5)$ & $4(2.2)$ \\
\hline Others* & $47(30.9)$ & $2(7.1)$ & $49(27.2)$ \\
\hline \multicolumn{4}{|l|}{ Hemato-oncology } \\
\hline Malignant lymphoma & $12(7.8)$ & $3(10.7)$ & $15(8.3)$ \\
\hline Leukemia & $6(3.9)$ & $1(3.5)$ & $7(3.8)$ \\
\hline \multicolumn{4}{|l|}{ Number of medications } \\
\hline $1-5$ & $19(12.5)$ & $18(64.2)$ & $37(20.6)$ \\
\hline $6-10$ & $82(53.9)$ & $10(35.7)$ & $92(51.1)$ \\
\hline $11-15$ & $39(25.6)$ & - & $39(21.7)$ \\
\hline $16-20$ & $11(7.2)$ & - & $11(6.1)$ \\
\hline
\end{tabular}

*Carcinoma of nasal cavity, carcinoma of pancrease, carcinoma of oropharynx, osteosarcoma, carcinoma of postcricoid colon, carcinoma of maxilla, carcinoma of anal, carcinoma of gall bladder, carcinoma of hepatocellular, fibrillary astrocytoma, carcinoma of pyriform fossa, plemorphic rhabdomyosarcoma, carcinoma of rectosigmoid colon, microinvassive squamous cell carcinoma, carcinoma of tonsil, carcinoma of voccal cord, carcinoma of supraglotis, carcinoma of tongue, spindle cell sarcoma, carcinoma of buccal mucosa. pDDIs - Potential drug-drug interactions; HTN - Hypertension

Majority of the pDDIs were seen in patients in the age group of $50-59$ years $(33.5 \%)$ in our study. The study conducted by Riechelmann et al. ${ }^{[11]}$ showed the similar results, where the drug interactions were common in the age group of 58 years. Our study results are in contrast to the study conducted by Ko et al., ${ }^{[12]}$ in which the 


\begin{tabular}{lc}
\hline $\begin{array}{c}\text { Table 2: Frequency of potential drug-drug interactions } \\
\text { involving anticancer drugs }(\boldsymbol{n}=\mathbf{1 5 2})\end{array}$ \\
\hline Interacting anticancer drug pair & $\begin{array}{c}\text { Number of } \\
\text { patients }(\%)\end{array}$ \\
\hline Alkylating agents + corticosteroids & $32(21.05)$ \\
Corticosteroids + mitotic inhibitors & $31(20.3)$ \\
Alkylating agents + mitotic inhibitors & $26(17.1)$ \\
Alkylating agents + anthracycline & $22(14.5)$ \\
Alkylating agents + antimetabolite & $20(13.15)$ \\
Anthracycline + antiemetic & $17(11.2)$ \\
Anthracycline + corticosteroids & $13(8.6)$ \\
Alkylating agents + antiemetic & $10(6.6)$ \\
Mitotic Inhibitor + NK1 receptor antagonist & $10(6.6)$ \\
Anthracycline + NK1 receptor antagonist & $7(4.6)$ \\
Anthracycline + antimetabolite & $6(3.9)$ \\
Corticosteroids + antimetabolite & $5(3.2)$ \\
Histamine H2 antagonist + antimetabolite & $4(2.6)$ \\
\hline NK1 - Neurokinin 1
\end{tabular}

maximum number of drug interactions in the age group was $>65$ years. This may be because organ dysfunction and comorbid conditions are more likely to be associated with older age. This further increases their risk for developing pDDIs.

In the present study, the most common tumor was found to be breast cancer (14.4\%). A comparable result was shown in the study conducted by van Leeuwen et al., ${ }^{[13]}$ where it was found to be $17.2 \%$. However, Mouzon et al. ${ }^{[14]}$ concluded that higher incidence was observed with gastrointestinal cancer $(27.9 \%)$. These findings were contradictory to the current study results.

The median number of medications received per patient in the present study was found to be 8 (range 1-21). A comparable result of median value of 9 in the range of 2-22 drugs was observed in the study conducted by van Leeuwen et al. ${ }^{[13]}$ However, comparatively lesser median value of 5 was reported by Riechelmann et al., ${ }^{[11]}$ making it not comparable with the present study results.

In this study, the most frequently prescribed anticancer agents were cisplatin $(14.5 \%)$ and docetaxel $(1.9 \%)$. The study results were comparable to the conducted by Mouzon et al., ${ }^{[14]}$ where it was found to be cisplatin (22.1\%) and docetaxel (13\%).

In the current study, cisplatin [49 (32.2\%)] was the most frequently drug involved in pDDIs. A comparable result was found in the study conducted by Mouzon et al., ${ }^{[14]}$ where it was found that cisplatin $(22.1 \%)$ was the most frequently involved anticancer drug in pDDIs.

Another important finding in the study was the incidence of pDDIs that may result in adverse events which include QT interval prolongation (40.1\%) and GI toxicity $(9.2 \%)$. A comparable result was found in the study conducted by

\begin{tabular}{|c|c|}
\hline Interacting supportive care drug pair & $\begin{array}{c}\text { Number of } \\
\text { patients (\%) }\end{array}$ \\
\hline Corticosteroids + aprepitant & $34(22.3)$ \\
\hline Histamine $\mathrm{H} 2$ antagonist + analgesics & $19(12.5)$ \\
\hline Antiemetic + opioids & $17(11.2)$ \\
\hline Dopamine agonist + histamine $\mathrm{H} 2$ antagonist & $17(11.2)$ \\
\hline Opioids + opioids & $17(11.2)$ \\
\hline Dopamine agonist + histamine $\mathrm{H} 2$ antagonist & $17(11.2)$ \\
\hline Tricyclic antidepressant + opioids & $16(10.5)$ \\
\hline Antiemetic + antibiotic & $10(6.6)$ \\
\hline Corticosteroids + anticonvulsant & $8(5.2)$ \\
\hline Corticosteroids + antiemetic & $7(4.6)$ \\
\hline Antihistamines + opioids & $7(4.6)$ \\
\hline Dopamine agonist + antiemetic & $7(4.6)$ \\
\hline PPIS + antifungal & $6(3.6)$ \\
\hline Corticosteroids + laxative & $6(3.9)$ \\
\hline Corticosteroids + antidysrhythmic & $6(3.9)$ \\
\hline Corticosteroids + NSAID & $5(3.3)$ \\
\hline NSAID + NSAID & $5(3.3)$ \\
\hline Hypnotic + opioids & $4(2.6)$ \\
\hline Hypnotic + hypnotic & $4(2.6)$ \\
\hline Tricyclic antidepressant + antihistamines & $4(2.6)$ \\
\hline Antiemetic + antifungal & $4(2.6)$ \\
\hline Laxative + antiemetic & $4(2.6)$ \\
\hline Opioids + anticonvulsant & $4(2.6)$ \\
\hline Corticosteroids + biguanide & $3(1.9)$ \\
\hline Corticosteroids + antifungal & $3(1.9)$ \\
\hline Antibiotic + anticonvulsant & $3(1.9)$ \\
\hline Bronchodilators + opioids & $3(1.9)$ \\
\hline Tricyclic antidepressant + antiemetic & $3(1.9)$ \\
\hline Antibiotic + laxative & $3(1.9)$ \\
\hline Antifungal + opioids & $3(1.9)$ \\
\hline
\end{tabular}

PPIs - Proton pump inhibitors; NSAID - Nonsteroidal anti-inflammatory drug

Leeuwen et al., ${ }^{[9]}$ where it was found to be QT interval prolongation (16.1\%) and GI toxicity (11.2\%).

In the present study, pain related to the cancer was treated with nonsteroidal anti-inflammatory drugs and opioids. These findings were consistent with the study conducted by Espinosa et al..$^{[15]}$ and van Leeuwen et al. ${ }^{[13]}$

The incidence of pDDIs in our hospital during the study period was $84.4 \%$. Contradictory results were shown in the study conducted by Riechelmann et al., ${ }^{[11]}$ where it was reported to be $31.34 \%$. This is due to that the patients involved in the study had more comorbidities; therefore, a large number of drugs were administered.

According to the severity of pDDIs, the study showed that $63.1 \%$ were moderate followed by major (26.1\%) and minor interactions $(10.1 \%)$. These findings were comparable to the study conducted by Leeuwen et al., ${ }^{[9]}$ where it was reported that most of the interactions were major $(33 \%)$ followed by moderate $(60.3 \%)$ and minor $(6 \%)$. 


\begin{tabular}{|c|c|c|c|}
\hline PDIs involving anti-cancer drug & Outcome & Severity & $\begin{array}{c}\text { Number of } \\
\text { patients }(\%)\end{array}$ \\
\hline \multicolumn{4}{|l|}{ Alkylating agents + corticosteroids } \\
\hline Cisplatin + dexamethasone & Muscle pain & Moderate & $32(21.05)$ \\
\hline \multicolumn{4}{|l|}{ Corticosteroids + mitotic inhibitors } \\
\hline Dexamethasone + paclitaxel & Reduces the blood level and effect of paclitaxel & Moderate & $16(10.5)$ \\
\hline Dexamethasone + vincristine & Reduces the blood level and effect of vincristine & Moderate & $15(9.8)$ \\
\hline \multicolumn{4}{|l|}{ Alkylating agents + mitotic inhibitors } \\
\hline Carboplatin/cisplatin + etoposide & Increases the effect of etoposide & Moderate & $6(3.9)$ \\
\hline Cisplatin + paclitaxel & Anemia, bleeding problem and nerve damage & Major & $3(1.9)$ \\
\hline Carboplatin + paclitaxel & Nerve damage & Major & $13(8.5)$ \\
\hline Carboplatin + docetaxel & Nerve damage & Major & $9(5.9)$ \\
\hline Cyclophosphamide + etoposide & Affect bone marrow function & Moderate & $1(0.6)$ \\
\hline \multicolumn{4}{|l|}{ Alkylating agents + anthracycline } \\
\hline Cyclophosphamide + doxorubicin & Cardiomyopathy & Major & $12(3.2)$ \\
\hline Carboplatin + doxorubicin & Increases doxorubicin exposure & Moderate & $1(0.6)$ \\
\hline Ifosfamide + doxorubicin & Affect bone marrow function & Moderate & $2(1.3)$ \\
\hline Cisplatin + epirubicin & Affect bone marrow function & Moderate & $6(3.9)$ \\
\hline Oxaliplatin + epirubicin & Affect bone marrow function & Moderate & $5(3.2)$ \\
\hline \multicolumn{4}{|l|}{ Alkylating agents + antimetabolite } \\
\hline Capecitabine + oxaliplatin & Affect bone marrow function & Moderate & $3(1.9)$ \\
\hline Cisplatin + fluorouracil & Affect bone marrow function & Moderate & $6(3.9)$ \\
\hline Cyclophosphamide + fluorouracil & Affect bone marrow function & Moderate & $1(0.6)$ \\
\hline Gemcitabine + carboplatin & Affect bone marrow function & Moderate & $2(1.3)$ \\
\hline Gemcitabine + oxaliplatin & Affect bone marrow function & Moderate & $2(1.3)$ \\
\hline Carboplatin + pemetrexed & Affect bone marrow function & Moderate & $6(3.9)$ \\
\hline Anthracycline + antiemetic & Affect bone marrow function & Moderate & \\
\hline Epirubicin/doxorubicin + palonosetron/ondansetron & Irregular heart beat & Moderate & $17(11.2)$ \\
\hline \multicolumn{4}{|l|}{ Anthracycline + corticosteroids } \\
\hline Doxorubicin + dexamethasone & Decreases doxorubicin exposure & Major & $13(8.6)$ \\
\hline \multicolumn{4}{|l|}{ Alkylating agents + antiemetic } \\
\hline Oxaliplatin + ondansetron & Irregular heart beat & Moderate & $1(0.6)$ \\
\hline Oxaliplatin + palonosetron & Irregular heart beat & Moderate & $4(2.6)$ \\
\hline Cyclophosphamide + ondansetron & Decreased cyclophosphamide systemic exposure & Moderate & $3(1.9)$ \\
\hline Ifosfamide + aprepitant & Increases the blood levels and effect of ifosfamide & Moderate & $1(0.6)$ \\
\hline \multicolumn{4}{|l|}{ Mitotic inhibitors + NK1 receptor antagonist } \\
\hline Docetaxel + aprepitant & Increases docetaxel exposure and toxicity & Major & $3(1.9)$ \\
\hline Paclitaxel + aprepitant & Decreases blood level and effect of paclitaxel & Moderate & $4(2.6)$ \\
\hline Aprepitant + etoposide & Increases blood level and effect of etoposide & Moderate & $6(3.9)$ \\
\hline Vincristine + aprepitant & Increases blood level and effect of vincristine & Moderate & $3(1.9)$ \\
\hline \multicolumn{4}{|l|}{ Anthracycline + NK1 receptor antagonist } \\
\hline Doxorubicin + aprepitant & Increases doxorubicin exposure & Major & $7(4.6)$ \\
\hline \multicolumn{4}{|l|}{ Anthracycline + antimetabolite } \\
\hline Fluorouracil + epirubicin & Affect bone marrow function & Moderate & $5(3.2)$ \\
\hline Fluorouracil + doxorubicin & Affect bone marrow function & Moderate & $1(0.6)$ \\
\hline \multicolumn{4}{|l|}{ Corticosteroids + antimetabolite } \\
\hline Dexamethasone + methotrexate & Increases blood level & Moderate & $5(3.2)$ \\
\hline \multicolumn{4}{|l|}{ Histamine $\mathrm{H} 2$ antagonist + antimetabolite } \\
\hline Ranitidine + pemetrexed & Increased blood level and effect of pemetrexed & Moderate & $4(2.6)$ \\
\hline
\end{tabular}

NK1 - Neurokinin 1; PDIs - Potential drug interactions

\section{Conclusion}

The present study shows that cancer patients are at a high risk of pDDIs. The incidence of pDDIs among cancer patients was $84.44 \%$. The most common interacting drug pair in the study population was found to be dexamethasone + aprepitant [41 (26.9\%)] followed by cisplatin + dexamethasone [32 (21.05)] and other interacting pairs. According to the severity of classification of pDDIs, 
Table 5: Interacting pair of supportive care drugs with outcome and severity $(n=152)$

\begin{tabular}{|c|c|c|c|}
\hline PDIs involving supportive care drugs & Outcome & Severity & $\begin{array}{c}\text { Number of } \\
\text { patients }(\%)\end{array}$ \\
\hline \multicolumn{4}{|l|}{ Corticosteroids + antiemetic } \\
\hline Dexamethasone + aprepitant & Increase systemic exposure to dexamethasone & Moderate & $41(26.9)$ \\
\hline \multicolumn{4}{|l|}{ Histamine $\mathrm{H} 2$ antagonist+analgesics } \\
\hline Chlorpheniramine + tramadol & Increased risk of seizures & Major & $19(12.5)$ \\
\hline \multicolumn{4}{|l|}{ Antiemetic + opioids } \\
\hline Ondansetron + tramadol & Reduced efficacy of tramadol & Moderate & $17(11.2)$ \\
\hline \multicolumn{4}{|l|}{ Dopamine agonist + histamine $\mathrm{H} 2$ antagonist } \\
\hline Ranitidine + domperidone & Increased QT interval prolongation & Major & $17(11.2)$ \\
\hline \multicolumn{4}{|l|}{ Opioids + opioids } \\
\hline Morphine + tramadol & Increased risk of CNS depression & Major & $9(5.9)$ \\
\hline Morphine + morphine & Respiratory depression & Major & $8(5.2)$ \\
\hline \multicolumn{4}{|l|}{ Tricyclic antidepressant + opioids } \\
\hline Amitriptyline + tramadol & Increased QT interval prolongation & Major & $13(8.6)$ \\
\hline Amitriptyline + morphine & Respiratory depression & Major & $3(1.9)$ \\
\hline \multicolumn{4}{|l|}{ Antibiotic + antiemetic } \\
\hline Azithromycin + ondansetron & Increased risk of QT interval prolongation & Major & $9(5.9)$ \\
\hline Ciprofloxacin + ondansetron & Increased risk of QT interval prolongation & Major & $1(0.6)$ \\
\hline \multicolumn{4}{|l|}{ Corticosteroids + anticonvulsant } \\
\hline Dexamethasone + phenytoin & Decreased dexamethasone effectiveness & Moderate & $8(5.2)$ \\
\hline \multicolumn{4}{|l|}{ Corticosteroids + antiemetic } \\
\hline Dexamethasone + ondansetron & Decreases the effect of ondansetron & Moderate & $7(4.6)$ \\
\hline \multicolumn{4}{|l|}{ Antihistamines + opioids } \\
\hline Diphenhydramine + tramadol & Increased risk of CNS depression & Major & $7(4.6)$ \\
\hline \multicolumn{4}{|l|}{ Dopamine agonist + antiemetic } \\
\hline Domperidone + ondansetron & Increased risk of QT interval prolongation & Major & $7(4.6)$ \\
\hline \multicolumn{4}{|l|}{ Antifungal + PPIs } \\
\hline Fluconazole + pantoprazole & Increased concentration of CYP2C19 & Moderate & $6(3.6)$ \\
\hline \multicolumn{4}{|l|}{ Corticosteroids + laxative } \\
\hline Dexamethasone + magnesium hydroxide/lactulose & Dehydration and hypokalemia & Moderate & $6(3.9)$ \\
\hline \multicolumn{4}{|l|}{ Corticosteroids + NSAID } \\
\hline Dexamethasone + diclofenac & Increases GI bleeding & Major & $3(1.9)$ \\
\hline Dexamethasone + mefenamic acid & Increases GI bleeding & Major & $2(1.3)$ \\
\hline \multicolumn{4}{|l|}{ NSAID + NSAID } \\
\hline Mefenamic acid + diclofenac & Increases GI bleeding & Major & $5(3.3)$ \\
\hline \multicolumn{4}{|l|}{ Hypnotic + opioids } \\
\hline Zolpidem + tramadol & Increased risk of CNS depression & Major & $4(2.6)$ \\
\hline \multicolumn{4}{|l|}{ Hypnotic + hypnotic } \\
\hline Zolpidem + zopiclone & Increased risk of CNS depression & Major & $4(2.6)$ \\
\hline \multicolumn{4}{|l|}{ Tricyclic antidepressant + antihistamines } \\
\hline Amitriptyline + chlorpheniramine & HTN, tachycardia and cardiac arrhythmia & Major & $2(1.3)$ \\
\hline Amitriptyline + diphenhydramine & Dry mouth, blurred, vision and drowsiness & Moderate & $2(1.3)$ \\
\hline \multicolumn{4}{|l|}{ Antiemetic + antifungal } \\
\hline Fluconazole + ondansetron & Increased risk of QT interval prolongation & Major & $4(2.6)$ \\
\hline \multicolumn{4}{|l|}{ Laxative + antiemetic } \\
\hline Magnesium sulfate + ondansetron & Irregular heart beat & Moderate & $4(2.6)$ \\
\hline \multicolumn{4}{|l|}{ Opioids + anticonvulsant } \\
\hline Phenytoin + morphine/tramadol & Dizziness, confusion and drowsiness & Moderate & $4(2.6)$ \\
\hline Corticosteroids + biguanide & & & \\
\hline Dexamethasone + metformin & Reduces the effectiveness of metformin & Moderate & $3(1.9)$ \\
\hline Corticosteroids + antifungal & & & \\
\hline Dexamethasone + fluconazole & Increased glucocorticoid exposure and risk for toxicity & Moderate & $3(1.9)$ \\
\hline
\end{tabular}

Contd... 


\begin{tabular}{|c|c|c|c|}
\hline \multicolumn{4}{|c|}{ Table 5: Contd... } \\
\hline PDIs involving supportive care drugs & Outcome & Severity & $\begin{array}{c}\text { Number of } \\
\text { patients }(\%)\end{array}$ \\
\hline \multicolumn{4}{|l|}{ Antibiotic + anticonvulsant } \\
\hline Sulfamethoxazole trimethoprim + phenytoin & Increased phenytoin toxicity & Moderate & $3(1.9)$ \\
\hline \multicolumn{4}{|l|}{ Bronchodilators + opioids } \\
\hline Theophylline + tramadol & Increases the risk of seizure & Major & $3(1.9)$ \\
\hline \multicolumn{4}{|l|}{ Tricyclic antidepressant + antiemetic } \\
\hline Amitriptyline + ondansetron & Increased risk of QT interval prolongation & Major & $3(1.9)$ \\
\hline \multicolumn{4}{|l|}{ Antibiotic + laxative } \\
\hline Azithromycin + aluminum hydroxide & Decreases the effect of azithromycin & Moderate & $2(1.3)$ \\
\hline Levofloxacin + magnesium hydroxide & Decreases the effect of levofloxacin & Moderate & $1(0.6)$ \\
\hline
\end{tabular}

PDIs - Potential drug interactions; PPIs - Proton pump inhibitors; NSAID - Nonsteroidal anti-inflammatory drug; CNS - Central nervous system; HTN - Hypertension; GI - Gastrointestinal

majority of them were moderate $(63.1 \%)$ followed by major $(26.1 \%)$ and minor (10.1\%) interactions. QT interval prolongation $(40.1 \%)$ and irregular heartbeat $(24.3 \%)$ were the most common outcomes of the pDDIs in cancer patients. To avoid harmful effects, screening of pDDIs should take place before administering the therapy. The physician and pharmacist must collaborate for the early detection and prevention of DDIs and their related harmful effects. Screening of pDDIs should take place before starting the therapy to avoid potential drug interactions. Clinical pharmacist in health-care team has a certain role in detecting interactions and making recommendations, to reduce medication-related problem and effective drug therapy to improve the quality of life in these patients.

\section{Financial support and sponsorship}

Nil.

\section{Conflicts of interest}

There are no conflicts of interest.

\section{References}

1. Köhler GI, Bode-Böger SM, Busse R, Hoopmann M, Welte T, Böger RH. Drug-drug interactions in medical patients: Effects of in-hospital treatment and relation to multiple drug use. Int J Clin Pharmacol Ther 2000;38:504-13.

2. Yancik R, Ries LA. Aging and cancer in America. Demographic and epidemiologic perspectives. Hematol Oncol Clin North Am 2000;14:17-23.

3. Hines LE, Murphy JE. Potentially harmful drug-drug interactions in the elderly: A review. Am J Geriatr Pharmacother 2011;9:364-77.

4. Scripture CD, Figg WD. Drug interactions in cancer therapy. Nat Rev Cancer 2006;6:546-58.

5. Ekincioglu AB, Demirkan K, Keskin B, Aslantas O, Ozdemir E. Potential drug interactions and side effects in an outpatient oncology clinic: A retrospective descriptive study. Eur J Hosp Sci Pract 2014;21:216-21.
6. Micromedex Drug Interactions. Available from: http:// www.micromedexsolutions.com/micromedex $2 /$ librarian/ CS/A81150/ND_PR/evidencexpert/ND_P/evidencexpert/ DUPLICATIONSHIELDSYNC/EFBA47/ND_PG/evidencexpert/ ND_B/evidencexpert/ND_AppProduct/evidencexpert/ND_T/ evidencexpert/PFActionId/evidencexpert.FindDrugInteractions ?navitem $=$ topInteractions\&isToolPage $=$ true. [Last accessed on 2017 Mar 18].

7. Medscape Multidrug Interaction Checker. Available from: http://www.reference.medscape.com/drug-interactionchecker. [Last accessed on 2017 Mar 18].

8. Riechelmann RP, Del Giglio A. Drug interactions in oncology: How common are they? Ann Oncol 2009;20:1907-12.

9. Leeuwen RW, Jansman FG, Deeman F, Piran F, Vencenten I, Rijnevld AW, et al. Drug-drug interactions in patients treated for cancer: A prospective study on clinical interventions. Ann Oncol 2010;25:146-64

10. Ussai S, Petelin R, Giordano A, Malinconico M, Cirillo D, Pentimalli $\mathrm{F}$, et al. A pilot study on the impact of known drug-drug interactions in cancer patients. J Exp Clin Cancer Res 2015;34:89.

11. Riechelmann RP, Tannock IF, Wang L, Saad ED, Taback NA, Krzyzanowska MK. Potential drug interactions and duplicate prescriptions among cancer patients. $\mathrm{J}$ Natl Cancer Inst 2007;99:592-600.

12. Ko Y, Tan SL, Chan A, Wong YP, Yong WP, Ng RC, et al. Prevalence of the coprescription of clinically important interacting drug combinations involving oral anticancer agents in Singapore: A retrospective database study. Clin Ther 2012;34:1696-704.

13. van Leeuwen RW, Brundel $\mathrm{DH}$, Neef $\mathrm{C}$, van Gelder $\mathrm{T}$, Mathijssen RH, Burger DM, et al. Prevalence of potential drug-drug interactions in cancer patients treated with oral anticancer drugs. Br J Cancer 2013;108:1071-8.

14. Mouzon A, Kerger J, D'Hondt L, Spinewine A. Potential interactions with anticancer agents: A cross-sectional study. Chemotherapy 2013;59:85-92.

15. Espino MF, Carrasco D, Salinas S. Potential drug-drug interactios in hospitalised haematological patients. Int $\mathrm{J}$ Clin Pharma 2016;3:512-620. 